Radio studies has blossomed in the USA in the past decade. Communities of the Air represents a part of that growth, one that has emerged from the literary end of cultural studies and the cultural studies end of science and technology studies. Half the authors are in English departments, one in German Studies, and the rest in a variety of Communications and Media Studies departments. All work at US universities. The

\title{
reading radio
} essays grew from panels presented in a Literature and Science stream at the 1998 MLA (Modern Language Association) conference.

In her introductory essay, Susan Squier

SUSAN MERRILL SQUIER (ED.)

Communities of the Air-Radio Century, Radio Culture

Duke University Press, Durham, 2003 ISBN 0-8223-3095-4

RRP US\$21.95 (pb)

argues that while radio history has 'provided an internalist perspective' on the development of radio technology and radio broadcasting, 'in contrast radio studies has moved beyond an internalist perspective to a critical and interdisciplinary one'. (3) But Squier classifies the work of two of the most influential recent radio historians-Michele Hilmes and Susan Douglas -as examples of 'communications studies scholarship on radio'. While both Hilmes and Douglas do teach in communications departments, defining their work as something quite outside radio history seems unhelpful, and leaves me wondering what does qualify as radio history for Squier. Hilmes's books Hollywood and Broadcasting from Radio to Cable, Radio Voices: American Broadcasting 1922-1952 and Only Connect: A Cultural History of Broadcasting in the United States and Douglas's Inventing American Broadcasting, 1899-1922 and Listening In: Radio and the American Imagination are surely important and revisionist historical works. 
Squier argues that her collection 'takes a markedly different approach to its material' than these works, because of its links to 'theoretical and cultural studies orientations'. The essays exemplify, she says, the "performative, practice-based orientation of cultural studies'. (8-9) But a great deal of the work in this collection is 'historical' in the sense of offering an interpretive reading of past texts, and little of it is overtly 'theoretical' in the sense of having as one of its primary aims a contribution to social or cultural theory. These essays are almost all case studies, marked by a determination and an ability to read closely and critically a few texts and sites of broadcasting. The volume marks the more widespread discovery by scholars with literary training that the sound texts of radio are available for close reading in the same way as written and filmic texts. Radio has been far less studied in this way than literature, film or television. The emergence of these essays out of the MLA surely signals some turning of the tide in radio's direction, and offers a fair sampling of the kind of interpretive work that post-canonical literary scholarship is now undertaking. Most of the essays engage in close critical analysis of radio programs, genres or performers. In contrast, Squier's concluding essay, 'Wireless Possibilities, Posthuman Possibilities: Brain Radio, Community Radio, Radio Lazarus', explores metaphors of radio in literature, film and radio drama. The readings are brief and exploratory, not yet connected into a larger argument, but Squier has identified an important new field of inquiry-the reflexive relationships between the technology of radio and the 'scientific, social, artistic, and medical' imaginations. (298)

On a more mundane level, all but two of the essays deal with radio in the USA, but only one of them includes the adjective 'American' in its title. Squier's introductory essay does make some gestures towards non-American contexts, not always successfully. '[R]adio began as a state monopoly everywhere in the West except the United States', she writes. (11) That seems to echo both the view widely propagated by the American broadcasting industry before the Second World War that the USA had the only free system of radio in the world, and the industry's obsessive distinguishing of American broadcasting from British, rather than the actual diversity of national broadcasting histories. Commercial broadcasters, for example, preceded public broadcasters in Australia and Canada, and public broadcasters in those nations never held a monopoly. It is a small point. This book is not particularly interested in the distinctiveness of the American broadcasting system or in comparisons with other nations, and there is a certain tiresomeness to the reiteration of the complaint from Australia or other smaller nations that Anglo-American work is not addressed to us, or is written in ignorance of our circumstances. But I do note the embeddedness of this collection in American perceptions and traditions.

One of the most powerful of those traditions in American radio history is the telling of a narrative of decline from a more diverse and communitarian past into the corporate and profit-driven present. American radio history 
has variously dated this decline to the 1934 Communications Act, to the rise of the networks in the 1930s, and to the many other periods in which diversity in broadcasting seemed to be under threat from economic consolidation. Looming over discussion of contemporary American radio in this book is the 1996 Telecommunications Act and the resultant drastic consolidation of ownership through the radio industry in the USA and the consequent re-networking of commercial radio. The Clear Channel corporation with its thousandstations in the USA alone stands as emblem of this process. Nina Huntemann, in 'A Promise Diminished: The Politics of Low-Power Radio', provides some useful discussion of this phenomenon. She finds in the Clear Channel annual reports an expression of the core philosophy of the new networks-'create it once, use it often'. (78) As one DJ works up to a hundred stations, there is a whole new level of loss of localism in broadcasting-the provision of local news, for example, is diminished or endangered. For Huntemann, as for several other authors in this collection, the story of the battle for low-power radio, and the opposition to it by an unlikely alliance of the big commercial broadcasters and National Public Radio, is a crucial and current story about the one chance to create some alternative to the consolidation of ownership and homogenisation of format. Huntemann's article is a report on a struggle in progress. It concludes on a note of uncertainty as to what will happen in Congress after the writing date.

Through this collection, then, present conflicts are situated as continuations of a long his- toric struggle. As Squier puts it, the 'low-power story demonstrates the same tension between centralized control and communicative pluralism, corporate capitalism and community service, that has characterized radio's technological development throughout its history'. (17) Steve Wurtzler in 'AT and T Invents Public Access Broadcasting in 1923: A Foreclosed Model for American Broadcasting' also sees great potential in micro-power broadcasting, and also locates it as the present site of an ongoing struggle for American broadcasting. Wurtzler understands low-power radio optimistically as part of a larger movement within American culture 'in which increasing numbers of citizens are redefining themselves as producers as well as consumers of media forms'. (54) He turns to the Bell System's 1923 plan for radio in the United States, which envisaged non-competitive, decentralised, local programming. The plan looked back to the telephone, Wurtzler suggests, but also forward to public access television. It was in Bell's commercial interests to propose a telephone-like system for the future of radio, but the plan nevertheless had great communitarian potential. (46) 'One can imagine (or perhaps fantasise about) an alternative history of American broadcasting', in which such public uses of the technology would have had a stronger basis. Wurtzler's essay offers a complex study of the inter-relationship of corporate self-interest and a sense of the public role and potential of broadcasting.

A number of the articles track commercial strategies in radio broadcasting, reporting and interpreting the choices made by advertisers and commercial broadcasters. More question- 
ing of the simple story of decline is Kathy Newman's important article 'The Forgotten Fifteen Million: Black Radio, Radicalism, and the Construction of the "Negro Market"'. The article discusses the attention that radio advertisers were giving to the purchasing power of African Americans from the 1940s and 'challenges the idea that postwar consumer culture was marked by the standardization of the consumer'. (110) The context here is the rise of black radio, from the widely noted success of WDIA, Memphis, in the 1940s, to the hundreds of stations that were targeting African American audiences by the end of the 1950s. Newman argues that "participation in mainstream commercial life might have positive consequences for marginalized groups'. (110) It was not only the mainstreaming implicit in being wooed by the major producers and advertisers of consumer goods, but also the segmented address to African American consumers that had unintended positive effects. Newman sees a connection between the postwar commercial acknowledgment of the coherence and significance of the black radio market and the use of commercial boycotts in the civil rights movement of the 1950s and 1960s.

Newman's title comes from a 1949 article in Sponsor magazine. In her article, as in others in the collection, the scholar follows the commercial insiders-the new scholarly discovery was becoming commercial common sense in the 1950s. Lauren Goodlad's 'Packaged Alternatives: The Incorporation and Gendering of "Alternative" Radio' also trails and puzzles over commercial broadcasting strategies. The article analyses the programming of three Seattle stations that play 'alternative' music. Here we are back to the story of decline into the profitdriven and corporate present. Goodlad believes that the 1996 Telecommunications Act 'completed the redefinition of the public and its interest from a model based on citizenship to one based on consumption'. (134) The article details her realisation that the post-punk music of the mid-1980s, which she had enjoyed as a young adult on an 'alternative' commercial station on Long Island, was already itself a commodity and a market category, and that its orientation towards UK-produced 'class-and gender-bending post-punk masquerade' was a way of not engaging with contemporary African American music and the 'far more resistant boundaries of race'. (137) Unable, on reflection, to characterise the music radio of her youth as less commercial, Goodlad settles for arguing that it had a less objectionable gender politics. By the late 1990s, Seattle's corporateowned 'alternative' music stations were more or less overtly gendered in their address-KISS FM for women, The Mountain for older men and The End for younger men. Goodlad moved to Seattle and at first listened to The End, but noticed it becoming increasingly a station for a raucous young male audience, with a morning talk show featuring 'frequent discussion of sex and antics involving female nudity'. (145) Goodlad then discovered the local campus public radio station $\mathrm{KCMU}$, which played a range of different music. At first, longing for the alternative format of her youth, she found this station too eclectic. Then she realised it offered 'this rare public forum-this truer alternative'. (150) The essay is part self-critique, part fan 
autobiography. A postscript reports on changes at these Seattle stations in 2001. Goodlad writes that 'in the last few weeks' she has sometimes suspected a 'sea change' in gender attitudes at The End. There is an unfinished quality to the essay-has the station changed or not? - and a sense that the truth the scholar is on the trail of is the present commercial strategy of the station, itself of course a secret.

Goodlad found 'today's more rigid gender norms' responsible in part for the transformation of the Seattle stations. In her narrative the decline into corporate radio has been accompanied both by a reduction in civility between the sexes and a loss of interest in the androgynous address of the 'alternative' music and radio she remembered from the 1980s. (151) Gender analysis-both of the celebrate-thetransgressions and the patriarchy-persists variety-features strongly in several of the historical essays in this collection. Leah Lowe's " "If the Country's Going Gracie, So Can You": Gender Representation in Gracie Allen's Radio Comedy' examines Gracie Allen's 1940 comic campaign for president of the USA. Lowe finds 'transgressive power' in Allen's comedy, despite her participation in a 'derogatory stereotype' of women as silly and scatterbrained, for 'against the comic exhilaration and sheer fun of Gracie's campaign performances, George's reality seems inordinately dull, rule bound, and predictable'. $(237,239)$ In contrast, Mary Desjardins and Mark Williams in "Are You Lonesome Tonight?": Gendered Address in The Lonesome Gal and The Continental' discuss two postSecond World War shows considered 'blatantly suggestive' at the time for their 'openly gen- dered direct address'. (251) Jean King, the 'Lonesome Gal', began each radio show: 'I love you more than anyone else in the whole world'. The 'Lonesome Gal' was one result of a period of experimenting with the novelty of women as 'glamour disk jockeys'. But King over time transformed her radio persona into a more conventional housewifely advice giver. Renzo Cesana on Los Angeles local and then network television in the early 1950s was The Continental, offering sexually suggestive chat to a female audience constructed as objects of male fetishisation. That show was from the start, Desjardins and Williams argue, 'thoroughly engrained in patriarchal positionings of women'. (269) Bruce Campbell's 'Compromising Technologies: Government, the Radio Hobby, and the Discourse of Catastrophe in the Twentieth Century' offers the most categorical and pre-determined gender analysis in the volume. Campbell argues that, in the world of amateur radio, the 'discourse of catastrophe'the argument that amateur radio is socially valuable because amateur radio operators play an important role in responding to disastersfurther marginalises women in what has always been a very masculine hobby. The proportion of women among radio hobbyists remains small, Campbell reports, in part because the 'extra burdens of homemaking and child rearing' tend to leave women with 'less free time to participate in amateur disaster relief'. (69)

Adrienne Munich's 'In the Radio Way: Elizabeth II, the Female Voice-Over, and Radio's Imperial Effects' discusses some radio performances of the young Elizabeth and offers a far more processual analysis of gender in the 
making. In 1940, the fourteen-year-old princess broadcast on the BBC Children's Hour from Windsor Castle, a performance that 'set the tone for the family-oriented position of the future queen's radio voice'. (218) Munich offers a nuanced discussion of the significance of the family and imperial setting of the broadcast, and a closer attention to voice than is evident in most of the essays in this collection. There is a psychoanalytic inflection to her analysis: 'The configuration of an authoritative girl's voice countering patriarchal authority constitutes a regressive pull to a primary object of desire'. (223) This is one of the most 'theoretical' essays in the collection, and-read together perhaps with Leah Lowe on Gracie Allen's voice-also one of the most effective in opening up the possibilities of a new kind of radio studies.

Another cluster of essays deal with the specialised discourses of poetry and science on the radio, and asks not about radio as such but about what radio can enable or prevent in these areas. Laurence Breiner's 'Caribbean Voices on the Air: Radio, Poetry, and Nationalism in the Anglophone Caribbean' reports on the BBC's 'Caribbean Voices', a literary program that ran from the end of the Second World War until 1958. The program broadcast from London readings of fiction, poetry and drama by West Indians, and helped create an imagined Anglophone West Indian identity. Breiner argues that the program encouraged the development of Caribbean poetry, and that the fact that the metropolitan outlet most available to West Indian poets was aural rather than written had beneficial effects. (99) In 'Not Hearing Poetry on Public Radio', Martin Spinelli comes to a very different conclusion about the way radio has worked for poetry on National Public Radio in the USA in the recent past. Spinelli offers a sharp and frankly literary assessment of the way poetry and poets are used on the NPR program Fresh Air, and concludes pessimistically that the program will only feature poetry that is 'narrative' or 'identity-based'. While the interest of a generalist program in reading poetry autobiographically is perhaps not surprising, Spinelli sees this as something more diagnosable-'a fear of anything that exposes the materiality or structure of means of communication'. (210) Equally pessimistic is Donald Ulin's 'Science Literacies: The Mandate and Complicity of Popular Science on the Radio', which is also largely about American public radio. He shows most interestingly the way funding and other exigencies lead to the production of short science spots that privilege universal and counter-intuitive knowledge over the less startling, local and observational material that might better convey something of the process of science rather than merely its results. (170-1)

What makes this a book? Perhaps soon, radio studies will have specialised to the point that a volume such as this, of fairly miscellaneous radio-related studies, will no longer be possible. As conference papers, these were reports from the field. As a book, some of the unfinished stories can be a little more frustrating. What did happen to low-power radio in the US Congress? Has the Seattle station moved away from its masculinist programming? This is not a book in the sense of being something concluded and conclusive. But as a series of 
skilled and engaged exemplars of contemporary American, literary-inflected radio studies, this volume marks an important moment. The collection is stronger on gender than on class or race, stronger on close reading than on new framing narratives. But there is much to be admired here. The best of this work pays attention to the sound qualities of the texts it studies, and engages in the kind of processual analysis which shows radio making, as well as reflecting, social hierarchies and distinctions. A recent international conference on radio has reinforced the impression that outside the USA, radio studies have not yet been revived with this kind of vigour and imagination. ${ }^{1}$ This book will serve as a challenge and a stimulus to those studying other national broadcasting systems.

DAVID GOODMAN teaches American history at the University of Melbourne.

1. 'The Radio Conference-A Transnational Forum' held at the University of Wisconsin, Madison, July 2003. 